\title{
Assessment of Various Techniques of Cholecystectomy: A Comparative Study
}

\author{
R. D. Sharma ${ }^{1}$ \\ ${ }^{1}$ Associate Professor, Department of General Surgery, Government Medical College, Bharatpur, Rajasthan, India.
}

\section{Abstract}

Background: Gallbladder disease is one of the most common procedures done with more than 1.2 million cholecystectomies done annually. The technique of performing LC has undergone many changes and variations. Hence; the present study was undertaken for assessing efficacy of various techniques of Laparoscopic cholecystectomy. Subjects and Methods: A total of 90 patients were enrolled in the present study and were broadly divided into three study groups as follows: Group A: Patients who underwent single port LC, Group B: Patients who underwent three port LC, and Group C: Patients who underwent Four port LC. Preoperative work up included evaluation of a complete history and physical examination, and radiological examinations including abdominal ultrasound. All the patients underwent LC according to their respective groups under the hands of skilled and experienced surgeons. All the postoperative follow-up details of all the patients were recorded. Results: Significant results were obtained while comparing the mean duration of surgery among subjects of all the three study groups. No-significant results were obtained while comparing the mean duration of hospital stay and incidence of complications among subjects of the three study groups. Conclusion: All the three techniques can be used with equal efficacy among subjects of the three study groups. However; in terms of duration of surgery, three port techniques was better in comparison to other two techniques.

Keywords: Cholecystectomy, Laparoscopic, Incision

Corresponding Author: Dr. R. D. Sharma, Associate Professor, Department of General Surgery, Government Medical College, Bharatpur, Rajasthan, India.

Received: August 2019

Accepted: August 2019

\section{Introduction}

Gallbladder disease is one of the most common procedures done with more than 1.2 million cholecystectomies done annually. Before 1991, an open technique was the standard procedure for cholecystectomy. This usually included performing an intraoperative cholangiogram, and patients usually had a 2 to 6-day postoperative in-house stay. With the advent of laparoscopic surgery and the laparoscopic cholecystectomy in the early 1990s, the gold standard for cholecystectomy has changed to a laparoscopic approach. ${ }^{[1]}$ This method showed a $30 \%$ increase in the overall performance of elective cholecystectomies. Today, 92\% of all cholecystectomies are done laparoscopically. There are several indications in performing open cholecystectomies, and this procedure remains an important part of training for the general surgery resident. ${ }^{[2,3]}$

Laparoscopic cholecystectomy (LC) since its inception in 1989 has become the gold standard treatment for gall stone disease. The technique of performing LC has undergone many changes and variations. Several surgeons have tried to reduce the size and number of ports to improve cosmetic and postoperative outcomes and developed their own different versions. The standard technique of performing LC is to use 4 ports. ${ }^{[4]}$ Newer, less invasive techniques, such as natural orifice transluminal endoscopic surgery (NOTES) and single incision laparoscopic cholecystectomy (SILC), are currently being investigated as alternatives to the traditional 4-port laparoscopic removal. Safety data and definitive benefits of these less invasive procedures are lacking. ${ }^{[5,6]}$

Hence; under the light of above mentioned data, the present study was undertaken for assessing efficacy of various techniques of Laparoscopic cholecystectomy.

\section{Subjects and Methods}

The present study was conducted in the department of General Surgery, Government Medical College, Bharatpur, Rajasthan, India and it included assessment of efficacy of various techniques of Laparoscopic cholecystectomy. Ethical approval was obtained from institutional ethical committee and written consent was obtained after explaining in detail the entire research protocol. A total of 90 patients were enrolled in the present study and were broadly divided into three study groups as follows: Group A: Patients who underwent single port LC, Group B: Patients who underwent three port LC, Group C: Patients who underwent Four port LC.

Complete demographic profile of all the patients was obtained. Blood samples were taken preoperatively and were sent to laboratory for assessment of hematological and 
biochemical profile. Preoperative work up included evaluation of a complete history and physical examination, and radiological examinations including abdominal ultrasound. Ultrasonography confirmed the presence of gall bladder stones in all patients. All the patients underwent LC according to their respective groups under the hands of skilled and experienced surgeons. All the postoperative follow-up details of all the patients were recorded. All the results were recorded in Microsoft excel sheet and were analyzed by SPSS software. Mann-Whitey U test and chi square test were used for assessment of level of significance.

\section{Results}

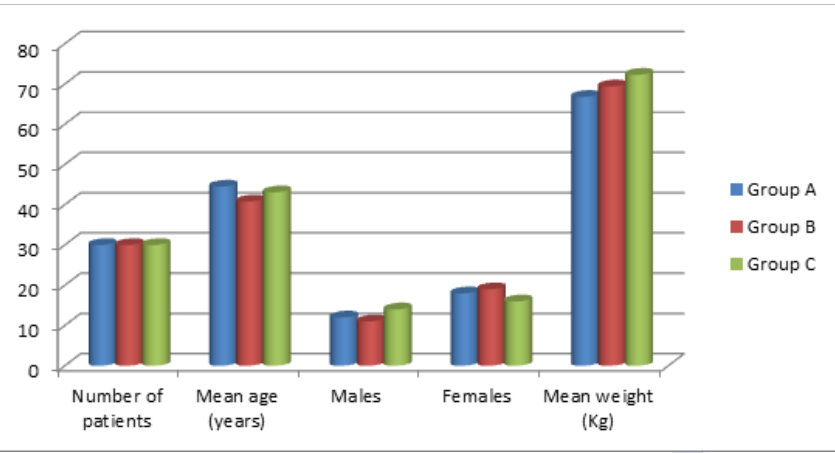

Figure 1: Demographic profile

Table 1: Conversion rate in all the study groups

\begin{tabular}{|l|l|l|l|l|}
\hline Parameter & Group A & Group B & Group C & p- value \\
\hline $\begin{array}{l}\text { Conversion } \\
(\mathrm{n})\end{array}$ & 6 & 1 & - & $\begin{array}{l}0.00 \\
\text { (Significant) }\end{array}$ \\
\hline $\begin{array}{l}\text { Conversion } \\
(\%)\end{array}$ & 20 & 3.3 & - & \\
\hline
\end{tabular}

Table 2: Occurrence of complications

\begin{tabular}{|l|l|l|l|l|}
\hline Complications & Group A & Group B & Group C & p- value \\
\hline Liver injury & 1 & 0 & 0 & 0.09 \\
\hline Vessel injury & 1 & 1 & 0 & \\
\cline { 1 - 4 } $\begin{array}{l}\text { Bleeding from } \\
\text { liver bed injury }\end{array}$ & 0 & 1 & 1 & \\
\hline
\end{tabular}

Table 3: Mean duration of surgery and mean duration of
hospital stay
\begin{tabular}{|l|l|l|l|l|}
\hline Parameter & Group A & Group B & Group C & p- value \\
\hline $\begin{array}{l}\text { Mean } \\
\text { duration of } \\
\text { surgery } \\
\text { (minutes) }\end{array}$ & 72.8 & 45.3 & 42.8 & $\begin{array}{l}0.00 \\
\text { (Significant) }\end{array}$ \\
\hline $\begin{array}{l}\text { Men duration } \\
\text { of hospital } \\
\text { stay (days) }\end{array}$ & 2.35 & 1.92 & 2.12 & 0.15 \\
\hline
\end{tabular}

In the present study, a total of 90 patients were enrolled and were broadly divided into three study groups with 30 patients in each group. Mean age of the patients of the group A, group B and group C was 44.5, 40.8 and 43.1 years respectively. There were 18,19 and 16 females in group $\mathrm{A}, \mathrm{B}$ and $\mathrm{C}$ respectively. The conversion rate in the group A was found to be 20 percent, whereas conversion rate in the Group B and 3.3 percent. Liver injury, vessel injury and bleeding from liver bed injury were the common complications encountered in the present study. In the present study, mean duration of surgery among patients of Group A, group B and group C was found to be 72.8 minutes, 45.3 minutes and 42.8 minutes. Significant results were obtained while comparing the mean duration of surgery among subjects of all the three study groups. Mean duration of hospital stay among subjects of group A, B and $\mathrm{C}$ was found to be $2.35,1.92$ and 2.12 days respectively. No-significant results were obtained while comparing the mean duration of hospital stay among subjects of the three study groups.

\section{Discussion}

Conventional laparoscopic cholecystectomy (CLC) with three or more ports remains the 'gold standard' for cholecystectomy. Although the postoperative pain is generally less intense and lasts a shorter time than that following open cholecystectomy, postoperative pain and effective analgesic treatment after laparoscopic cholecystectomy has remained a clinical challenge. Inadequate postoperative pain control can delay patient's recovery, lengthen the hospital stay and increase morbidity and costs. ${ }^{[4-6]}$

Recently, single-incision laparoscopic cholecystectomy (SILC), which involves placing multiple instruments through a single umbilical access point, has emerged as a potential less-invasive alternative to CLC. The potential advantages of SILC include decreased scarring and decreased incisional pain. Although there are some reports regarding decreased postoperative pain compared with the conventional approach, to date, the benefits of SILC have yet to be formally proven. Recently, some systematic metaanalyses were presented that compare postoperative pain and complications after SILC and CLC. ${ }^{[7-9]}$

Hence; under the light of above mentioned data, the present study was undertaken for assessing various techniques of Laparoscopic cholecystectomy.

In the present study, a total of 90 patients were enrolled and were broadly divided into three study groups with 30 patients in each group. Mean age of the patients of the group A, group B and group C was 44.5, 40.8 and 43.1 years respectively. There were 18,19 and 16 females in group $\mathrm{A}, \mathrm{B}$ and $\mathrm{C}$ respectively. The conversion rate in the group A was found to be 20 percent, whereas conversion rate in the Group B and 3.3 percent. Liver injury, vessel injury and bleeding from liver bed injury were the common complications encountered in the present study. In comparative study done by Amanda $\mathrm{J}$ et al 22 single port cholecystectomy was performed on 20 consecutive patients for biliary dyskinesia, symptomatic cholelithiasis or acute cholecystitis. Tri Port and a combination of straight and articulating instruments were utilised. Patients characteristics and outcomes were reviewed and a comparison was made with the prior 20 consecutive laparoscopic cholecystectomies performed using the three port technique. The three port cholecystectomy had a mean 
time of $65.7 \mathrm{~min}$ and patients had an average Body Mass Index (BMI) of 28.16. The time required for first single port cholecystectomy was $160 \mathrm{~min}$ with sequential improvement to the 6 th case of 66 min with a mean of 68.2 min for the last 15 single port cases. The average patient BMI was 30.24. No major complications occurred. 16 patients were discharged the same day, 2 patients were discharged one day after surgery, one patient 2 nd day postoperative and 1 patient fourth day post operative due to anticoagulation needs of the patient. They concluded that Single Port Cholecystectomy patients have less hospital stay. ${ }^{[9]}$

In the present study, mean duration of surgery among patients of Group A, group B and group C was found to be 72.8 minutes, 45.3 minutes and 42.8 minutes. Significant results were obtained while comparing the mean duration of surgery among subjects of all the three study groups. Mean duration of hospital stay among subjects of group A, B and $\mathrm{C}$ was found to be $2.35,1.92$ and 2.12 days respectively. No-significant results were obtained while comparing the mean duration of hospital stay among subjects of the three study groups. Harsha HS et al investigated the technical feasibility, safety and benefit of three-port laparoscopic cholecystectomy (LC) over the conventional standard fourport LC as routine setup. A total of 50 patients willing to participate in the study with valid consent were allocated into two groups by computer generated chit system. The first group, three-port LC group consisted of 25 cases and the second group, the standard four-port LC group consisted of 25 cases were analyzed for the following outcome measures namely conversion rates, operating time, intraoperative complications, post-operative pain score, analgesic requirement and hospital stay. The mean operating time was comparable in both groups. Postoperative pain was significantly less in three-port group $(\mathrm{P}$ $<0.008)$ and analgesic requirement $(\mathrm{P}<0.001)$ when compared with the four-port group. Hospital stay was significantly less in three-port group compared with the four-port group $(\mathrm{P}<0.004)$ owing to post-operative pain score. There was no statistical difference in the complications rate in both groups; gallbladder perforation
$(\mathrm{P}=0.691)$, bile leakage $(\mathrm{P}=1.00)$ and bleeding from liver bed $(\mathrm{P}=0.691)$. Three-port LC is technically safe and feasible with less post-operative pain score, less analgesic requirement, less hospital stay with comparable operating time and complications when compared to four-port LC. ${ }^{[10]}$

\section{Conclusion}

From the above results, it can be concluded that all the three techniques can be used with equal efficacy among subjects of the three study groups. However; in terms of duration of surgery, three port techniques was better in comparison to other two techniques. However; further studies are recommended.

\section{References}

1. Pan MX, Jiang ZS, Cheng Y, Xu XP, Zhang Z, Qin JS, et al. Singleincision vs three-port laparoscopic cholecystectomy: Prospective randomized study. World J Gastroenterol. 2013;19:394-8.

2. Way LW, Stewart L, Gantert W, et al. Causes and prevention of laparoscopic bile duct injuries. Ann Surg. 2003; 237: 460-469

3. Shäfer M, Läuper M, Krähenbühl L. Trocar and Veress needle injuries during laparoscopy. Surg Endosc. 2001; 15: 275-280

4. Hanney RM, Carmalt HL, Merrett N, Tait N. Use of the Hasson cannula producing major vascular injury at laparoscopy. Surg Endosc. 1999; 13: 1238-1240.

5. Azawi DA, Houssein N, Rayis AB, McMahon D, Hehir DJ. Three-port versus four-port laparoscopic cholecystectomy in acute and chronic cholecystitis. BMC Surg. 2007;7:1-6.

6. Piskun G, Rajpal S. Transumbilical laparoscopic cholecystectomy utilizes no incisions outside the umbilicus. J Laparoendosc Adv Surg Tech A. 1999;9:361-4.

7. Bhoyrul S, Vierra MA, Nezhat CR, Krummel TM, Way LW. Trocar injuries in laparoscopic surgery. J Am Coll Surg. 2001; 192: 677-683

8. Hasson HM. Open laparoscopy as a method of access in laparoscopic surgery. Gynaecol Endosc. 1999; 8: 353-362

9. Amanda J.Kravetz MD,Douglas Idai Do,Maren Barron MD PhD MBA,Michael A.Kia D O.The learning curve with single port cholecystectomy.2009;3:332-336.

10. Harsha H S, Gunjiganvi M, Singh C, Moirangthem G S. A study of three-port versus four-port laparoscopic cholecystectomy. J Med Soc 2013;27:208-11

Copyright: () the author(s), 2019. It is an open-access article distributed under the terms of the Creative Commons Attribution License (CC BY 4.0), which permits authors to retain ownership of the copyright for their content, and allow anyone to download, reuse, reprint, modify, distribute and/or copy the content as long as the original authors and source are cited.

How to cite this article: Sharma RD. Assessment of Various Techniques of Cholecystectomy: A Comparative Study. Asian J. Med. Res. 2019;8(3):SG11-SG13.

DOI: dx.doi.org/10.21276/ajmr.2019.8.3.SG4

Source of Support: Nil, Conflict of Interest: None declared. 